\title{
Pathological Gambling
}

National Cancer Institute

\section{Source}

National Cancer Institute. Pathological Gambling. NCI Thesaurus. Code C94335.

A disorder characterized by a preoccupation with gambling and the excitement that gambling with increasing risk provides. Pathological gamblers are unable to cut back on their gambling, despite the fact that it may lead them to lie, steal, or lose a significant relationship, job, or educational opportunity. 